\title{
BMJ Global Health Association between early essential newborn care and breastfeeding outcomes in eight countries in Asia and the Pacific: a cross-sectional observational -study
}

Zhao Li, ${ }^{1}$ Priya Mannava, ${ }^{1}$ John Charles Scott Murray, ${ }^{1}$ Howard Lawrence Sobel, ${ }^{1}$ Annie Jatobatu, ${ }^{2}$ Anthony Calibo, ${ }^{3}$ Baldan Tsevelmaa, ${ }^{4}$ Bounnack Saysanasongkham, ${ }^{5}$ Divinal Ogaoga, ${ }^{2}$ Edward Joseph Waramin, ${ }^{6}$ Elizabeth Mary Mason, ${ }^{7}$ Hiromi Obara, ${ }^{8}$ Hoang Thi Tran, ${ }^{9}$ Hoang Anh Tuan, ${ }^{10}$ Jacqueline Kitong, ${ }^{11}$ Jessica Mara Yaipupu, ${ }^{12}$ Kannitha Cheang, ${ }^{13}$ Maria Asuncion Silvestre, ${ }^{14}$ Outhevanh Kounnavongsa, ${ }^{15}$ Pamela Putney, ${ }^{16}$ Pham Thi Quynh Nga, ${ }^{17}$ Rathavy Tung, ${ }^{18}$ Sano Phal, ${ }^{13}$ Shogo Kubota, ${ }^{15}$ Sidonn Krang, ${ }^{19}$ Simon Burggraaf, ${ }^{20}$ Sommana Rattana, ${ }^{5}$ Tao Xu, ${ }^{21}$ Tuohong Zhang, ${ }^{22}$ Ulziikhutag Enkhmaa, ${ }^{4}$ Vanya Delgermaa, ${ }^{23}$ Y Meng Chhour, ${ }^{24}$ Western Pacific Region Early Essential Newborn Care Working Group

To cite: Li Z, Mannava P, Murray JCS, et al. Association between early essential newborn care and breastfeeding outcomes in eight countries in Asia and the Pacific: a cross-sectional observational -study. BMJ Global Health 2020;5:e02581. doi:10.1136/ bmjgh-2020-002581

Handling editor Sanni Yaya

Received 3 April 2020

Revised 27 May 2020

Accepted 18 June 2020

Check for updates

(C) Author(s) (or their employer(s)) 2020. Re-use permitted under CC BY-NC. No commercial re-use. See rights and permissions. Published by BMJ.

For numbered affiliations see end of article.

Correspondence to Dr Howard Lawrence Sobel; sobelh@who.int

\section{ABSTRACT}

Objective To explore the association between early essential newborn care (EENC) policy, practice and environmental interventions and breastfeeding outcomes.

Design Cross-sectional observational study.

Setting 150 national, provincial and district hospitals implementing EENC in eight countries in East Asia and the Pacific.

Participants 1383 maternal interviews, chart reviews and environmental assessments during 2016 and 2017.

Main outcome measures Exclusive breastfeeding (EBF), that is, feeding only breastmilk without other food or fluids since birth and before discharge, and, early breastfeeding initiation, that is, during skin-to-skin contact (SSC) with the mother without separation.

Results Fifty-nine per cent of newborns initiated breastfeeding early and $83.5 \%$ were EBF. Duration of SSC showed a strong dose-response relationship with early breastfeeding initiation. SSC of at least $90 \mathrm{~min}$ was associated with 368.81 (95\% Cl 88.76 to 1532.38 , $p<0.001$ ) times higher early breastfeeding. EBF was significantly associated with SSC duration of 30-59 min (OR 3.54, 95\% Cl 1.88 to 6.66, p<0.001), 60-89 min (OR $5.61,95 \% \mathrm{Cl} 2.51$ to $12.58, \mathrm{p}<0.001)$ and at least $90 \mathrm{~min}$ (OR $3.78,95 \% \mathrm{Cl} 2.12$ to $6.74, \mathrm{p}<0.001$ ) regardless of delivery mode. Non-supine position (OR $2.80,95 \% \mathrm{Cl} 1.90$ to $4.11, \mathrm{p}<0.001)$, rooming-in (OR $5.85,95 \% \mathrm{Cl} 3.46$ to $9.88, \mathrm{p}<0.001$ ), hospital breastfeeding policies (OR 2.82 , $95 \% \mathrm{Cl} 1.97$ to $4.02, \mathrm{p}<0.001$ ), quality improvement mechanisms (OR 1.63, 95\% $\mathrm{Cl} 1.07$ to $2.49, \mathrm{p}=0.02$ ) and no formula products (OR $17.50,95 \% \mathrm{Cl} 5.92$ to 51.74 , $\mathrm{p}<0.001$ ) were associated with EBF.

\section{Key questions}

What is already known?

- Early essential newborn care (EENC) interventions delivered around childbirth and in the early newborn period can improve maternal and newborn outcomes.

- Immediate skin-to-skin contact (SSC) between mother and baby after birth is associated with increased rates of exclusive breastfeeding.

- The optimal timing and duration of SSC after birth has not yet been established.

What are the new findings?

- The duration of uninterrupted SSC showed a strong dose-response relationship with early initiation of breastfeeding through $90 \mathrm{~min}$ after birth.

- Exclusive breastfeeding at discharge was strongly associated with uninterrupted SSC of 30-59, 60-89 and above $90 \mathrm{~min}$ after birth, regardless of mode of delivery.

- This is the first study to demonstrate an association between SSC duration and early and exclusive breastfeeding outcomes in low-income and middleincome countries in Asia and the Pacific.

Conclusion EENC policy, practice and environmental interventions were associated with breastfeeding outcomes. To maximise the likelihood of early and EBF, newborns, regardless of delivery mode, should receive immediate and uninterrupted SSC for at least $90 \mathrm{~min}$. 


\section{Key questions}

What do the new findings imply?

- EENC intrapartum and immediate newborn care interventions, with a focus on promoting prolonged uninterrupted SSC and eliminating early separations, should be practised at childbirth to maximise breastfeeding outcomes.

- Effective introduction of EENC requires a team-based quality improvement approach that uses self-collected data to update policies, protocols, staff roles and patient flow to support SSC and breastfeeding.

\section{INTRODUCTION}

Initiation of breastfeeding within 1 hour of birth and exclusive breastfeeding (EBF) for at least 6 months are associated with reduced newborn, infant and child morbidity and mortality and have potential long-term benefits for both mother and child. ${ }^{12}$ Countries in east Asia and the Pacific have the lowest early initiation $(32 \%)^{3}$ and EBF $(22 \%)^{4}$ rates globally. Numerous factors limit breastfeeding including widespread use of outdated or harmful clinical practices at birth. ${ }^{56}$

To address these gaps, countries in east Asia and Pacific endorsed the Action Plan for Healthy Newborn Infants in the Western Pacific Region (2014-2020). ${ }^{7}$ This plan focuses on delivery of early essential newborn care (EENC), a package of simple evidence-based interventions delivered around birth shown to prevent or treat the most important causes of newborn morbidity and mortality. ${ }^{8}$ EENC promotes early and exclusive breastfeeding through improved birth practices, prolonged skin-to-skin contact (SSC) of at least $90 \mathrm{~min}$ between mothers and newborns, ${ }^{9}$ timely breastfeeding when newborns exhibit feeding cues (typically 15-90 min after birth $)^{10} 11$ and elimination of both unnecessary early separation from the mother and promotion of infant formula. ${ }^{12-14}$ Concurrently, breastfeeding support at delivery, lactation management ${ }^{15}$ and hospital policies on breastfeeding, rooming-in and prohibition of formula company promotional materials and sponsored products are encouraged. ${ }^{1617}$

Implementation of EENC began in 2014 in eight countries accounting for over $95 \%$ of neonatal deaths in east Asia and the Pacific: Cambodia, China, Lao People's Democratic Republic, Mongolia, Papua New Guinea, Philippines, Solomon Islands and Viet Nam. The approach included introduction of a standard package of intrapartum and newborn care interventions, practice-based clinical coaching and use of hospital quality improvement (QI) teams, routine self-assessments and action planning to reinforce optimal clinical practices, policies and work environments. ${ }^{18} 19$ In addition, external EENC facility assessments were done biennially with direct support and supervision from ministries of health.

Assessment data from 150 hospitals in eight countries provided an opportunity to examine the relationship between EENC interventions and breastfeeding outcomes. Defining the optimal timing of initiation and duration of SSC is particularly important because it influences changes in birthing room practices, staffing and environments. SSC is defined differently in effectiveness studies, with initiation ranging from immediately after birth to up to 21 hours and duration from less than 1 hour, to over 1 hour without more precise time measures. ${ }^{9}$ In addition, studies often do not specify whether SSC is uninterrupted, which may influence effectiveness. The WHO currently recommends immediate or early SSC (within 10 min of birth) based on available data suggesting that early initiation improves rates of exclusive breastfeeding at hospital discharge to 1 month of age. ${ }^{20}$ SSC for 1 hour after birth is recommended although this recommendation is not based on data from pooled effectiveness studies, and there are currently no guidelines on optimal duration. ${ }^{91}$

The East Asia and Pacific Region is undergoing rapid economic development with expenditures on infant formula high and rising quickly. ${ }^{22}$ Action at health facilities to limit formula use can support enforcement of the code of marketing of breast milk substitutes and related World Health Assembly resolutions. ${ }^{23}$ Strategies for improving early and exclusive breastfeeding practices are therefore critically important. The objective of the study was to explore the association between EENC policy, practice and environmental interventions and breastfeeding outcomes.

\section{METHODS}

\section{Sample and data sources}

Secondary analysis of cross-sectional childbirth and newborn care hospital assessments conducted in 20162017 was undertaken for eight EENC implementing countries. The assessments used standard WHO methods and tools. ${ }^{24}$

The sampling frame for each assessment was hospitals that had begun EENC implementation. At least three national implementing hospitals were included, when possible. Between 6 and 15 implementing provinces were then randomly selected. In each sampled province, the provincial hospital and two randomly selected district hospitals were included. All six EENG implementing hospitals in China and seven in Solomon Islands were included.

Trained assessors visited sampled hospitals for 1-2 days. Ten mothers of live stable singleton term babies who had delivered in the hospital at least $90 \mathrm{~min}$ prior to the interview were selected. Stillbirths, newborn deaths and newborns requiring separation for care at birth were excluded. For the 123/150 (82.0\%) of hospitals with 10 or fewer postpartum mothers available on the day of assessment, all mothers were selected. For the remaining $27(18.0 \%)$ hospitals, with more than 10 postpartum women available, systematic random sampling was used to select 10 from the total. Standard checklists were used for conducting maternal interviews and chart reviews, 
observing hospital policies and environments and validating QI records (meeting minutes, assessment reports and action plans).$^{24}$ Data were reviewed for completeness and accuracy on the day of the visit and entered into an Excel database, which was cleaned and independently validated by Ministries of Health and WHO. Final country assessment data were validated by the WHO Western Pacific Region EENC Independent Review Group as a part of regional reporting of country progress. ${ }^{19}$

\section{Definition of variables}

Dependent variables

The primary outcome of interest, EBF, was defined as feeding only breastmilk with no other food or fluids except medications since birth. Postnatal women were asked whether their baby had received any food or fluids other than breastmilk, from any source, since the birth of their baby through the time of the interview. This therefore represents a measure of breastfeeding status prior to discharge. A secondary outcome of interest, early initiation of breastfeeding, was defined as the completion of the first breastfeed (attached with deep sucking) by a newborn during SSC, without separation from the mother for any reason.

\section{Independent variables}

Independent variables for analysis were selected if they were collected by the EENC standard practice assessment checklists and had been associated or potentially associated with breastfeeding outcomes in WHO data synthesis reviews developed using the Grading of Recommendations Assessment, Development and Evaluation methodology methodology: mode of delivery, companion of choice during childbirth, non-supine position and food and fluids during labour, SSC, rooming-in of mother and baby, families having infant formula company products, promotional infant formula materials visible in the hospital, hospital breastfeeding policy available and EENC QI approach in place at the hospital. ${ }^{20} 2125$ Mode of delivery was defined as caesarean section or vaginal delivery. Companion of choice was defined as the mother having a non-staff companion with her during the first and second stages of labour. Non-supine position was defined as mother being on her side, sitting-up, lying with the backrest raised, standing, walking, squatting or any position except flat on her back for some or all of the first and second stages of labour. Encouraged to eat and drink was defined as mother being offered food and fluids and encouraged to eat and drink when she wanted to during first and second stages of labour.

SSC was defined as direct contact between the bare skin of the mother and baby initiated within $1 \mathrm{~min}$ of birth. Duration was defined as the period of direct SSC contact without separation from the mother for any reason, with duration categorised into five groups: less than 10, 10-29, $30-59,60-89$ and $90 \mathrm{~min}$ and above.

Rooming-in was defined as mother and baby staying in the same room during the entire hospital stay, with separations of no more than 1 hour not considered violations of rooming-in.

Infant formula company-sponsored products were defined as any products or paraphernalia produced by infant formula companies, including formula, baby bottles, towels, t-shirts and clothing. Promotional infant formula materials included brochures, pamphlets, posters, websites, videos or other information with company logos or brand names.

Hospital breastfeeding policy was defined as a written policy prohibiting use of infant formula company products and other linkages with infant formula companies displayed and visible on the wall of patient care rooms.

A hospital EENC QI approach was defined as the presence of a functional EENC team that had done at least two EENC quality assessments with documentation available in the previous 12 months.

\section{Analysis}

Data on the variables of interest were extracted from the EENC country implementation assessment database, cleaned and recoded into categorical values. Logical inference was applied during data cleaning to reduce the number of values with missing data as a result of data entry errors. This was done by cross-validating values between selected variables of interest for this study and the EENC country implementation assessment database. For example, a missing value in variable 'Exclusive breastfeeding' was coded as 'no' if the value in another variable 'baby fed with anything other than breastfeed during the entire hospital stay' was 'Yes'. A total of six variables had missing data, ranging between $0.14 \%$ and $4.3 \%$ of total sample size (table 1). Sensitivity analysis was carried out by replacing missing variables with the largest and smallest value in the dataset. Sensitivity analysis of all variables resulted in less than 0.1 changes to the ORs and showed no changes in the $95 \%$ CIs and statistical significance.

Bivariate and multivariate models were constructed to investigate relationships between EENC clinical practice and hospital environment variables and early and exclusive breastfeeding outcomes. Listwise deletion of missing data were automatically applied during the logistic regression analyses and that resulted in variance of denominators in the results table. Multicollinearity were checked in multivariate logistic regression models using the variance inflation factor test. Data were analysed using the Intercooled Stata V.15.0 statistical package.

\section{Ethical procedures and approvals}

Ministries of Health classified the EENC assessments as programmatic reviews of routine management practices of trained professionals and advised no ethical clearance was required for either the primary reviews or the secondary analysis. The assessments did not influence the time or place of deliveries or staff responsible for care, require deviations from accepted clinical practices, nor impose significant additional burden on patients or staff. 
Table 1 Proportion of mothers and babies receiving intrapartum and newborn care practices, assessments of 150 health facilities, eight countries, 2016-2017

\begin{tabular}{|c|c|c|}
\hline Variables included in the analysis & $\begin{array}{l}\mathrm{n} / \mathrm{N}(\%) \text { or median } \\
\text { (IQR) }\end{array}$ & $\begin{array}{l}\text { Mothers/babies with missing data } n, \% \\
\text { ( } N=1383 \text { total sample) }\end{array}$ \\
\hline Vaginal delivery & $1133 / 1372(82.6)$ & $11(0.8)$ \\
\hline $\begin{array}{l}\text { Mother had a companion of choice during labour and } \\
\text { childbirth }\end{array}$ & $299 / 1379(21.7)$ & $4(0.3)$ \\
\hline Mother adopted a non-supine position during delivery & $662 / 1382(47.9)$ & $1(0.1)$ \\
\hline Mother encouraged to eat and drink during labour & $938 / 1377(68.1)$ & $6(0.4)$ \\
\hline Duration of skin-to-skin contact after birth & - & $60(4.3)$ \\
\hline No SSC at birth & $121 / 1323(9.1)$ & - \\
\hline SSC duration $<10 \mathrm{~min}$ & $133 / 1323(10.1)$ & - \\
\hline SSC duration $10-29$ min & $177 / 1323(13.4)$ & - \\
\hline SSC duration 30-59 min & $234 / 1323(17.7)$ & - \\
\hline SSC duration $60-89 \mathrm{~min}$ & $150 / 1323(11.3)$ & - \\
\hline SSC duration $\geq 90 \mathrm{~min}$ & $508 / 1323(38.4)$ & - \\
\hline Baby initiated breastfeeding before separation & 786/1342 (58.6) & $41(3.0)$ \\
\hline Rooming-in practice & $1310 / 1383(94.7)$ & $0(0.0)$ \\
\hline Baby exclusively breastfed & $1155 / 1383(83.5)$ & $0(0.0)$ \\
\hline
\end{tabular}

Informed verbal consent was secured prior to maternal interviews, and no personal identifiers used in assessments. Feedback on assessment findings was given to facility staff and managers immediately or within 2 days of the assessment visit.

\section{RESULTS}

A total of 150 health facilities from eight countries were assessed between 2016 and 2017, of which 21.3\% (32) were tertiary hospitals and $78.7 \%$ (118) first-level referral hospitals. About half $(73 / 150)$ of the health facilities were in the Philippines and Viet Nam. The median number of annual live births per health facility in 2016 was 1925 (IQR: 1176-3950) (table 2).

A total of 1383 mothers were interviewed at a median of 27 hours (IQR: 12-56) after birth (table 1). Missing data are noted for six variables, with SSC practice variables missing in 60 cases $(4.3 \%)$ and for early initiation of breastfeeding before separation in 41 cases (3\%). Most mothers, 1133/1372 (82.6\%) had a vaginal delivery, with close to half $(662 / 1382,47.9 \%)$ adopting a non-supine position during delivery. A total of 1202/1323 (90.9\%) babies were placed in SSC with their mother, with over one-third of babies $(508 / 1323,38.4 \%)$ remaining in SSC

Table 2 Characteristics of the study sample, assessments of 150 health facilities, eight countries, 2016-2017

\section{Number of health facilities assessed}

\begin{tabular}{|c|c|c|c|c|}
\hline Country & $\begin{array}{l}\text { Total } \\
\% \text { (n) }\end{array}$ & $\begin{array}{l}\text { Tertiary hospitals } \\
\% \text { (n) }\end{array}$ & $\begin{array}{l}\text { First-level referral } \\
\text { hospitals } \\
\% \text { (n) }\end{array}$ & $\begin{array}{l}\text { Annual live births in facilities } \\
\text { assessed, } 2016 \\
\text { Median (IQR) }\end{array}$ \\
\hline Cambodia & $10.0(15)$ & $9.4(3)$ & $10.2(12)$ & 1415 (712-2086) \\
\hline China & $4.0(6)$ & $9.4(3)$ & $2.5(3)$ & 6527 (3397-8851) \\
\hline Laos PDR & $12.0(18)$ & $12.5(4)$ & $11.9(14)$ & $1892(1357-3799)^{\star}$ \\
\hline Mongolia & $16.7(25)$ & $12.5(4)$ & $17.8(21)$ & 1724 (1218-2478) \\
\hline Papua New Guinea & $4.0(6)$ & $3.1(1)$ & $4.2(5)$ & $1745(1001-3000)$ \\
\hline Philippines & $18.7(28)$ & $40.6(13)$ & $12.7(15)$ & 2868 (1358-6805)† \\
\hline Solomon Islands & $4.7(7)$ & $3.1(1)$ & $5.1(6)$ & 644 (265-985)‡ \\
\hline Viet Nam & $30.0(45)$ & $9.4(3)$ & $35.6(42)$ & 2800 (1251-5299)§ \\
\hline Total & $100.0(150)$ & $100.0(32)$ & $100.0(118)$ & 1925 (1176-3950) \\
\hline
\end{tabular}

*Data from 17 hospitals.

†Data from 27 hospitals.

‡Data from 6 hospitals.

$\S$ Estimates based on Ministry of Health data on total live births per province. 
Table 3 Bivariate analysis of the relationship between SSC duration after birth and early initiation of breastfeeding, assessment of 150 hospitals, eight countries, 2016-2017

\begin{tabular}{|c|c|c|c|c|}
\hline \multirow[b]{2}{*}{ Independent variable } & \multicolumn{4}{|l|}{ Term babies $(\mathrm{N}=1303)$} \\
\hline & $\begin{array}{l}\text { Did not complete first } \\
\text { breastfeed during SSC, n (\%) }\end{array}$ & $\begin{array}{l}\text { Completed first breastfeed } \\
\text { during SSC, } n(\%)\end{array}$ & OR $(95 \% \mathrm{Cl})$ & $P$ value \\
\hline SSC duration $<10 \mathrm{~min}$ & $119(89.5)$ & $14(10.5)$ & 6.06 (1.34 to 27.29$)$ & 0.02 \\
\hline SSC duration 10-29 min & $111(62.7)$ & $66(37.3)$ & 30.62 (7.31 to 128.22$)$ & $<0.001$ \\
\hline$S S C$ duration $\geq 90 \mathrm{~min}$ & $62(12.2)$ & $444(87.8)$ & 368.81 (88.76 to 1532.38$)$ & $<0.001$ \\
\hline Total & $518(39.8)$ & $785(60.2)$ & - & - \\
\hline
\end{tabular}

SSC, skin-to-skin contact.

for at least $90 \mathrm{~min}$ after birth. Close to $60 \%$ of babies (786/1342) completed a first breastfeed while in SSC. A high proportion of babies, $1155 / 1383(83.5 \%)$, were exclusively breast fed at the time of interview (table 1).

\section{SSC duration and early initiation of breastfeeding}

Bivariate logistic regression was performed on 1303 term babies with data available for duration of SSC and timing of breastfeeding. Data were not available for 80 newborns $(5.7 \%)$ either because the mother did not recall the duration of SSC or timing of the first breastfeed or because of data recording errors. Of the 1303 newborns analysed, $785(60.2 \%)$ received an early breastfeed before separation (table 3 ). A strong dose-response effect was evident between duration of SSC and the first breastfeed compared with no SSC at birth (table 3, figure 1).

\section{Birth practices, SSC duration and EBF}

Data on EBF were available for all newborns sampled. The EBF rate for all newborns combined was $83.5 \%$, with rates ranging from $67.8 \%$ for babies not placed in SSC to as high as $92.7 \%$ for babies receiving 60-90 min of uninterrupted SSC. Total numbers of mothers and newborns varied slightly between variables because of missing data (table 1). Bivariate logistic regression found significant associations between $\mathrm{EBF}$ and birth practices (vaginal delivery, companion of choice, non-supine position and eating and drinking during first and second stages

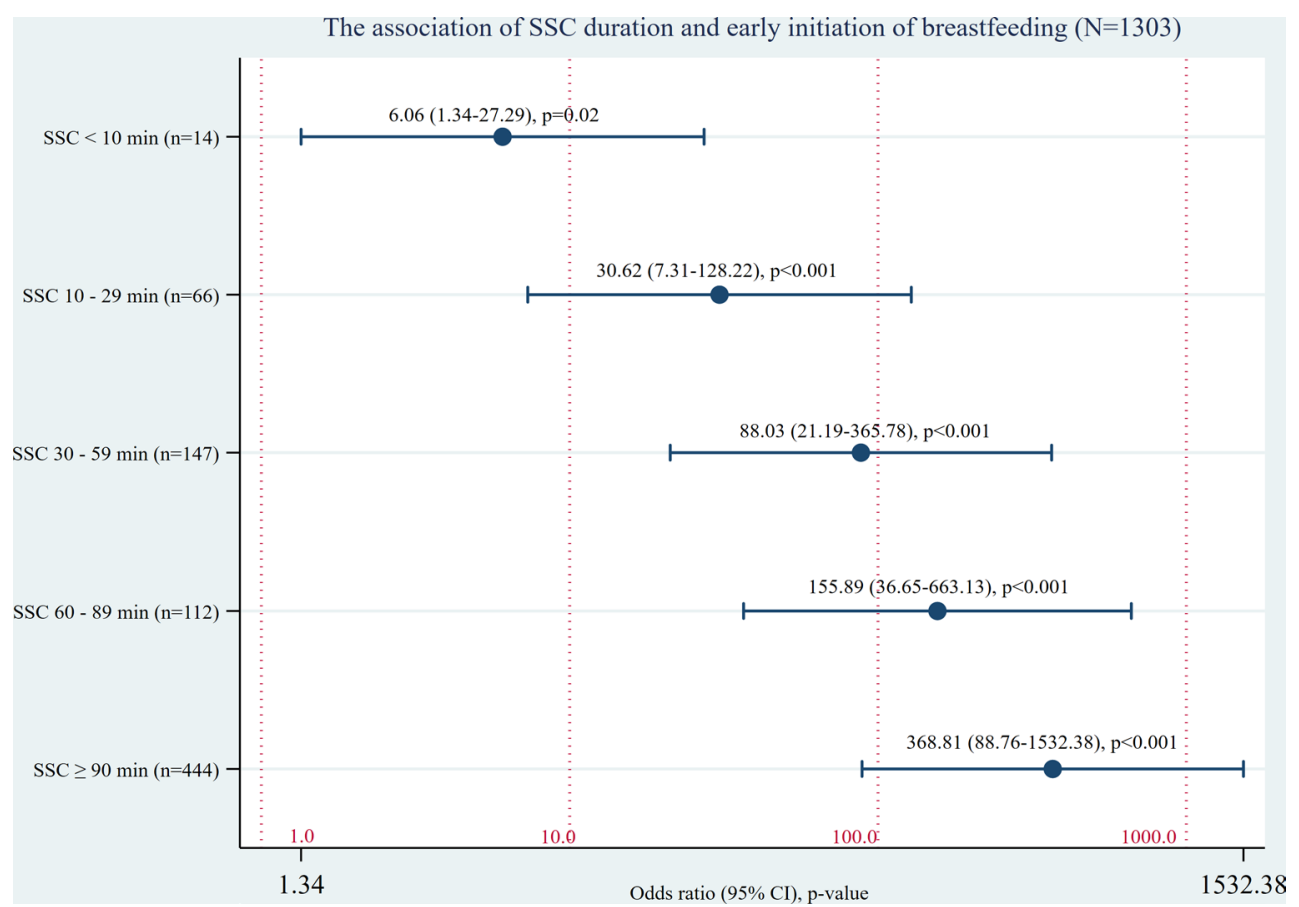

Figure 1 Bivariate analysis of the relationship between SSC duration after birth and early initiation of breastfeeding, assessments of 150 hospitals, eight countries, 2016-2017.

SSC, skin-to-skin contact. 
Table 4 Bivariate and multivariate logistic regressions of the relationship between key EENC clinical practice steps and exclusive breastfeeding, assessments in 150 hospitals, eight countries, 2016-2017

Term babies $(\mathrm{N}=1383)$

\begin{tabular}{|c|c|c|c|c|c|c|}
\hline Independent variable & Not EBF, n (\%) & EBF, n (\%) & $\begin{array}{l}\text { Bivariate OR } \\
(95 \% \mathrm{Cl})\end{array}$ & $P$ value & $\begin{array}{l}\text { Multivariate OR } \\
(95 \% \mathrm{Cl})\end{array}$ & $P$ value \\
\hline \multicolumn{7}{|l|}{ During delivery process } \\
\hline \multicolumn{7}{|l|}{ Mode of delivery } \\
\hline Caesarean section & 70 (29.3) & $169(70.7)$ & 1 & - & & \\
\hline Vaginal delivery & $156(13.8)$ & 977 (86.2) & 2.59 (1.87 to 3.59$)$ & $<0.001$ & 0.96 (0.58 to 1.58$)$ & 0.86 \\
\hline \multicolumn{7}{|l|}{ Companion of choice } \\
\hline No companion of choice & $194(18.0)$ & $886(82.0)$ & 1 & - & & \\
\hline $\begin{array}{l}\text { Having a companion of } \\
\text { choice }\end{array}$ & $33(11.0)$ & $266(89.0)$ & $1.76(1.19$ to 2.62$)$ & 0.005 & 0.89 (0.56 to 1.43$)$ & 0.64 \\
\hline \multicolumn{7}{|l|}{ Position during delivery } \\
\hline Supine position & $59(8.9)$ & $603(91.1)$ & 1 & - & & \\
\hline Non-supine position & $169(23.5)$ & $551(76.5)$ & $3.13(2.28$ to 4.31$)$ & $<0.001$ & $2.80(1.90$ to 4.11$)$ & $<0.001$ \\
\hline \multicolumn{7}{|c|}{ Eating and drinking during labour } \\
\hline $\begin{array}{l}\text { Not allowed to eat or } \\
\text { drink }\end{array}$ & $108(24.6)$ & $331(75.4)$ & 1 & - & & \\
\hline $\begin{array}{l}\text { Encouraged to eat and } \\
\text { drink }\end{array}$ & $118(12.6)$ & $820(87.4)$ & 2.27 (1.70 to 3.03$)$ & $<0.001$ & 1.30 (0.91 to 1.87$)$ & 0.15 \\
\hline \multicolumn{7}{|c|}{ Skin-to-skin contact (SSC) duration after birth } \\
\hline No SSC & $39(32.2)$ & $82(67.8)$ & 1 & - & & \\
\hline SSC duration $<10 \mathrm{~min}$ & $32(24.1)$ & $101(75.9)$ & $1.50(0.87$ to 2.60$)$ & 0.15 & $1.52(0.81$ to 2.87$)$ & 0.20 \\
\hline SSC duration 10-29 min & $38(21.5)$ & $139(78.5)$ & 1.74 (1.03 to 2.94$)$ & 0.04 & 1.55 (0.84 to 2.86$)$ & 0.16 \\
\hline SSC duration 30-59 min & 27 (11.5) & $207(88.5)$ & 3.64 (2.10 to 6.34$)$ & $<0.001$ & 3.54 (1.88 to 6.66$)$ & $<0.001$ \\
\hline SSC duration $60-89 \mathrm{~min}$ & $11(7.3)$ & $139(92.7)$ & $6.01(2.92$ to 12.38$)$ & $<0.001$ & $5.61(2.51$ to 12.58$)$ & $<0.001$ \\
\hline SSC duration $\geq 90 \mathrm{~min}$ & $51(10.0)$ & $457(90.0)$ & 4.26 (2.64 to 6.88$)$ & $<0.001$ & 3.78 (2.12 to 6.74$)$ & $<0.001$ \\
\hline
\end{tabular}

EBF, exclusive breastfeeding; EENC, early essential newborn care.

of labour) and duration of SSC after birth (30-59 min, $60-89 \mathrm{~min}$ and longer than $90 \mathrm{~min})$. When pooled in the multivariate model, mode of delivery and all birth practices except non-supine position in labour were no longer significantly associated with EBF. SSC duration of 30-59 min, 60-89 min and longer than $90 \mathrm{~min}$ remained significantly associated with EBF (table 4).

\section{Hospital environment and EBF}

The families of $1.4 \%$ (20/1383) babies in 11 health facilities in three countries had products sponsored from infant formula companies during their hospital stay. One-third $(36 \%)$ of facilities had a written policy prohibiting use of infant formula company products. Rates of EBF ranged from $25.0 \%$ for newborns born in facilities with formula company-sponsored products available, to $89.7 \%$ in facilities with written orders prohibiting the use of formula company presents posted in patient care areas. Total numbers of mothers and newborns varied slightly between variables because of missing data. In both bivariate and multivariate analyses, EBF was significantly associated with baby rooming-in, no infant formula companysponsored products, a posted written policy prohibiting use of infant formula company products and a functional EENC QI approach (table 5).

\section{DISCUSSION}

This study of 1383 newborns born in 150 hospitals implementing EENC across eight countries in Asia and the Pacific found a strong dose-response relationship between the duration of uninterrupted SSC and breastfeeding initiation. Multivariate regression analysis found exclusive breastfeeding before discharge to be 3.54-5.61 times more likely if uninterrupted SSC was maintained for at least $30 \mathrm{~min}$ after birth, regardless of mode of delivery. Use of a non-supine delivery position was the only birth practice significantly associated with EBF at discharge. At the facility level, rooming-in of mother and baby, a hospital breastfeeding policy, a functional EENC QI mechanism and the absence of infant formula company-sponsored products were all significantly associated with $\mathrm{EBF}$ at discharge, while the absence of infant formula promotional materials like posters and pamphlets was not. Higher rates of EBF at discharge are likely to be associated with higher rates of $\mathrm{EBF}$ in the 
Table 5 Bivariate and multivariate logistic regression analyses of the relationship between hospital environment measures and exclusive breastfeeding, assessment in 150 hospitals, eight countries, 2016-2017

\begin{tabular}{|c|c|c|c|c|c|c|}
\hline \multirow[b]{2}{*}{ Independent variable } & \multicolumn{6}{|c|}{ Term babies $(\mathrm{N}=1383)$} \\
\hline & Not EBF, n (\%) & EBF, n (\%) & $\begin{array}{l}\text { Bivariate OR } \\
(95 \% \mathrm{Cl})\end{array}$ & $P$ value & $\begin{array}{l}\text { Multivariate OR } \\
(95 \% \mathrm{Cl})\end{array}$ & $P$ value \\
\hline \multicolumn{7}{|l|}{ Rooming-in practice } \\
\hline $\begin{array}{l}\text { Baby did not stay with the } \\
\text { mother during the entire } \\
\text { hospital stay }\end{array}$ & $35(48.0)$ & $38(52.0)$ & 1 & - & 1 & - \\
\hline $\begin{array}{l}\text { Baby stayed with the } \\
\text { mother during the entire } \\
\text { hospital stay (rooming in) }\end{array}$ & $193(14.7)$ & 1117 (85.3) & 5.33 (3.29 to 8.65$)$ & $<0.001$ & 5.85 (3.46 to 9.88$)$ & $<0.001$ \\
\hline \multicolumn{7}{|c|}{ Infant formula company-sponsored products } \\
\hline $\begin{array}{l}\text { Infant formula company- } \\
\text { sponsored products } \\
\text { present }\end{array}$ & $15(75.0)$ & $5(25.0)$ & 1 & - & 1 & - \\
\hline $\begin{array}{l}\text { No infant formula } \\
\text { company-sponsored } \\
\text { products present }\end{array}$ & $213(15.6)$ & $1148(84.4)$ & $16.17(5.82$ to 44.96$)$ & $<0.001$ & $17.50(5.92$ to 51.74$)$ & $<0.001$ \\
\hline \multicolumn{7}{|c|}{ Hospital policy on prohibiting use of infant formula company products } \\
\hline $\begin{array}{l}\text { No written policy } \\
\text { presented }\end{array}$ & $173(20.4)$ & $674(79.6)$ & 1 & - & 1 & - \\
\hline $\begin{array}{l}\text { Posted written policy } \\
\text { prohibiting use of infant } \\
\text { formula company } \\
\text { products }\end{array}$ & $55(10.3)$ & $481(89.7)$ & 2.24 (1.62 to 3.11$)$ & $<0.001$ & 2.82 (1.97 to 4.02$)$ & $<0.001$ \\
\hline \multicolumn{7}{|c|}{ Promotional infant formula company materials inside hospital } \\
\hline $\begin{array}{l}\text { Having promotional } \\
\text { materials visible }\end{array}$ & $8(25.8)$ & $23(74.2)$ & 1 & - & 1 & - \\
\hline $\begin{array}{l}\text { No promotional materials } \\
\text { visible }\end{array}$ & $220(16.3)$ & $1132(83.7)$ & 1.79 (0.79 to 4.05$)$ & 0.16 & 1.60 (0.68 to 3.75$)$ & 0.28 \\
\hline \multicolumn{7}{|c|}{ Hospital's EENC quality control mechanism } \\
\hline $\begin{array}{l}\text { Not having a EENC } \\
\text { quality improvement } \\
\text { approach }\end{array}$ & $198(17.9)$ & $905(82.1)$ & 1 & - & 1 & - \\
\hline $\begin{array}{l}\text { EENC quality } \\
\text { improvement approach } \\
\text { established }\end{array}$ & $30(10.7)$ & $250(89.3)$ & $1.82(1.21$ to 2.74$)$ & 0.004 & $1.63(1.07$ to 2.49$)$ & 0.02 \\
\hline
\end{tabular}

EBF, exclusive breastfeeding; EENC, early essential newborn care.

postnatal period after discharge. ${ }^{9}{ }^{26}$ Although caesarean section is well known to limit breastfeeding ${ }^{14}$ and often imposes difficulties that lead to breastfeeding cessation, ${ }^{27}$ this study suggests that uninterrupted SSC, in the context of environmental and systems changes introduced as part of EENC implementation, mitigates the negative effects of caesarean section on EBF.

\section{Strengths and weaknesses of the study}

To our knowledge, this is the first study to demonstrate a significant relationship between breastfeeding outcomes and duration of uninterrupted SSC in lowincome and middle-income countries. These findings are consistent with those of a previous study showing a dose-response relationship between duration of SSC and EBF on discharge, conducted in 19 hospitals in California. ${ }^{28}$ However, the Californian study found an association between EBF and low durations of SSC, including $1-15 \mathrm{~min}$ and $16-30 \mathrm{~min}$. A second study conducted in Poland found a relationship between duration of SSC and duration of EBF over time for SSC of greater than 20 min in duration but not less. ${ }^{29}$

Across the 150 hospitals sampled in this study, the proportion of newborns' EBF before discharge ranged from $0 \%$ to $100 \%$, with an average rate of $83.5 \%$. This relatively high rate of EBF is likely to be due to EENC implementation in sampled hospitals that began incorporating EBF into routine practice with associated policy and systems changes in 2014. It is important to 
note therefore that findings are specific to this hospitalbased population and that they represent EBF practice at discharge, which may decline in the months following discharge.

The study used a cross-sectional design and therefore findings may not represent quality of hospital services across time that may change with case loads, case type, availability of staff or staff skills. Observation bias may influence staff practices and facility environments, such as the availability of infant formula, promotional materials and posted written policies. To minimise the risk of observation bias, health facility clinical staff in obstetric and postnatal wards were not informed in advance of the dates of assessment visits, and maternal interviews about birth practices were used. In $18 \%$ of hospitals, systematic random sampling of postpartum mothers allowed selection of those who had delivered in both daytime and night-time with different health staff and staffing patterns. In $82.0 \%$ of sampled facilities, fewer than 10 patients were available on the day of the assessment, and random sampling of patients was not possible. At these facilities, it was assumed that the available cases were not subject to any systematic bias by type of provider or how they were managed. Postpartum maternal interviews were subject to reporting and recall bias. Recall bias is likely to be reduced by the fact that interviews are conducted close to birth. In addition, validation of mothers' recall of immediate newborn care practices has shown high levels of agreement between observed and reported measures of initiation of SSC contact, duration of uninterrupted SSC contact, completion of the first breastfeed during uninterrupted SSC, reason for separation, 'rooming in' and EBF. ${ }^{18}$ Breastfeeding practices at the time of the postpartum interview were considered to represent breastfeeding practices at discharge. Since the median timing of interviews was 27 hours after birth, in settings where hospital admissions are rarely longer than 48 hours, it is believed that reported practices were unlikely to change. Because this study used available data from standard assessment tools, it was not able to control for other factors that may influence breastfeeding practice, including education, maternal infant-feeding intention measured prior to birth, smoking, race and ethnicity and intrapartum analgesia and anaesthesia. However, several of these factors have been shown previously not to confound the effect of duration on SSC on EBF at discharge. ${ }^{28}$ Analgesia is rarely used for routine vaginal births in the public health system in the focus countries assessed here, as is the case in many Asian countries. ${ }^{30}$ Future studies to examine these factors in detail in the East Asia and Pacific region may be warranted. In addition, this study did not include preterm babies who were not the focus of EENC until after 2017. Subsequent analyses of facility practice data should review practices for both term and preterm babies to identify differences in management of these two populations.

\section{Hypothesis for results}

There is a strong physiological basis for maintaining early and uninterrupted SSC between mother and baby. This unique period, coinciding with high levels of oxytocin in the mother and catecholamines in the newborn, promotes thermoregulation, early EBF, bonding, reduced stress, earlier expulsion of the placenta and reduced risk of bleeding in the mother among other benefits. ${ }^{9} 3132$ Physiological data show that readiness to breastfeed is highly variable between newborns, with the mean time of first breastfeed around $50 \mathrm{~min}$ postpartum; a high proportion require well over 1 hour to complete feeding. Longer periods of uninterrupted SCC therefore allow this process to be completed. ${ }^{10} 32$ Furthermore, by preventing separation, newborns are further protected from the negative consequences of harmful procedures including early cord clamping, routine suction and early bathing, which may slow down the readiness to breastfeed and have other negative health impacts. SSC is also often interrupted for routine care, including weighing and administration of vitamin $\mathrm{K}$ and vaccines, procedures that can be delayed until after $90 \mathrm{~min}$. EENC targets elimination of these harmful or unnecessary early practices and therefore promotes uninterrupted SSC and breastfeeding. The association of non-supine position in labour and EBF could theoretically be mediated by reductions in the duration of the first stage of labour that may contribute to an increased likelihood that mothers and babies are able to breastfeed early. ${ }^{33}$ No associations with companionship or use of food and fluids during childbirth were noted. Other studies suggest that presence of a companion may increase the likelihood of any and EBF, possibly by reducing duration of labour, use of pain relief and improving the birth experience. ${ }^{25}$

The association of EBF with rooming-in, written policies to forbid promotion of infant formula and absence of infant formula company-sponsored products is consistent with findings of previous studies. ${ }^{20}{ }^{22}{ }^{34}$ QI teams established to support EENC conduct regular assessments using standard tools that include birth and breastfeeding practices in delivery rooms and postnatal areas and identify areas for improvement and actions needed. Active QI teams are therefore likely to promote improved staff counselling and support for breastfeeding practices. These findings provide further evidence of the association between the availability of correct information and support to mothers and breastfeeding. ${ }^{35-38}$ Mothers who do not have social support or receive confusing messages ${ }^{39}$ negative influences from advertisements or inaccurate advice from health workers or relatives to use infant formula tend not to breastfeed or stop breastfeeding early. ${ }^{40-42}$

\section{Policy implications}

This study in hospitals implementing EENC suggests that stable term newborns born by either vaginal or caesarean section delivery should receive immediate $(<1 \mathrm{~min})$ and uninterrupted SSC for at least $90 \mathrm{~min}$ to maximise 
the likelihood of early and exclusive breastfeeding at discharge and that a non-supine position during labour, a practice currently recommended by WHO, may improve breastfeeding exclusivity. ${ }^{20}$

Since SSC of 30-59 min duration was associated with improved rates of EBF, this may be considered as a shortterm programme target in settings beginning implementation. However, improvements in EBF rates were most significant when SSC was maintained for $60-89 \mathrm{~min}$ and over $90 \mathrm{~min}$. Given the strong dose-response association between SSC duration and early initiation of breastfeeding before separation, the data suggest that the optimal duration of SSC should be at least $90 \mathrm{~min}$ to maximise the likelihood of both early and EBF. The study findings provide further evidence that changing early newborn care practices requires a broad-based approach to address policy norms and standards, attitudes of staff and systems barriers. For EENC implementation in countries in the Asia and Pacific Region, this begins with on-the-job clinical coaching using adult learning methodologies and includes establishing QI teams that conduct regular self-assessments, redefining staff roles and responsibilities to equitably distribute workload, reorganising space and ensuring availability of simple equipment and supplies. ${ }^{18}{ }^{43-45}$ Regular practice assessments using standard tools are essential for identifying gaps and making practice improvements. ${ }^{24}$ EENC has been rolled out and largely financed by Ministries of Health in countries with both high and low newborn mortality, ${ }^{19} 46$ with improvements in beneficial newborn care practices and reductions in newborn morbidity. ${ }^{18} 1945$ Nevertheless, achieving longer durations of uninterrupted SSC remains challenging, with $36 \%$ of term newborn babies receiving $90 \mathrm{~min}$ and $57 \%$ completing a breastfeed before separation from the mother across the region in 2017. ${ }^{19}$ These challenges apply equally to developed country settings, with SSC and EBF at hospital discharge often not practised, especially following caesarean births. ${ }^{47} 48$ These findings provide strong evidence that introduction of EENC policy, practice and environmental interventions during childbirth and in the early newborn period should be a key priority to help improve breastfeeding outcomes.

\footnotetext{
Author affiliations

${ }^{1}$ Maternal, Child Health and Quality and Safety, World Health Organization Regional Office for the Western Pacific, Manila, Philippines

${ }^{2}$ Maternal and Child Health Division, Ministry of Health of Solomon Islands, Honiara, Solomon Islands

${ }^{3}$ Disease Prevention and Control Bureau, Department of Health, Manila, Philippines ${ }^{4}$ Department of Medical Service, Mongolia Ministry of Health, Ulaanbaatar, Mongolia

${ }^{5}$ Department of Health Care and Rehabilitation, Ministry of Health, Lao People's Democratic Republic, Vientiane, Lao People's Democratic Republic

${ }^{6}$ Department of Population and Family Health Services, Government of Papua New Guinea National Department of Health, Port Moresby, National Capital District, Papua New Guinea

${ }^{7}$ Department of Infectious Disease Epidemiology, London School of Hygiene and Tropical Medicine, London, UK
}

${ }^{8}$ Division of Global Health Policy and Research, National Center for Global Health and Medicine, Shinjuku-ku, Tokyo, Japan

${ }^{9}$ Neonatal Department, Da Nang Hospital for Women and Children, Da Nang, Viet Nam

${ }^{10}$ Department of Maternal and Child Health, Government of Viet Nam Ministry of Health, Hanoi, Viet Nam

${ }^{11}$ Department of Maternal Child Health and Nutrition, World Health Organization Country Office for Philippines, Manila, Philippines

${ }^{12}$ Department of Maternal and Child Health, Office of the WHO Representative in Papua New Guinea, Port Moresby, Papua New Guinea

${ }^{13}$ Department of Maternal and Child Health, WHO Representative Office Cambodia, Phnom Penh, Cambodia

${ }^{14}$ Kalusugan ng Mag-Ina (KMl; translation - Health of Mother and Child), Quezon City, Philippines

${ }^{15}$ Department of Maternal and Child Health, Office of the WHO Representative in Laos PDR, Vientiane, Lao People's Democratic Republic

${ }^{16}$ International Consultant, Martha's Vineyard, Massachusetts, USA

${ }^{17}$ Department of Maternal and Child Health, Office of the WHO Representative in Viet Nam, Hanoi, Viet Nam

${ }^{18}$ National Maternal and Child Health Center, Royal Government of Cambodia Ministry of Health, Phnom Penh, Cambodia

${ }^{19}$ Department of Communicable Diseases Control, Royal Government of Cambodia Ministry of Health, Phnom Penh, Cambodia

${ }^{20}$ Department of Maternal and Child Health, Office of the WHO Representative in Solomon Islands, Honiara, Solomon Islands

${ }^{21}$ National Center for Women and Children's Health, Child Health Care Department, Chinese Center for Disease Control and Prevention, Beijing, China

${ }^{22}$ Department of Health Systems, Office of the WHO Representative in China, Beijing, China

${ }^{23}$ Department of Maternal and Child Health, Office of the WHO Representative in Mongolia, Ulaanbaatar, Mongolia

${ }^{24}$ Under-Secretary of State for Health, Royal Government of Cambodia Ministry of Health, Phnom Penh, Cambodia

Acknowledgements The authors acknowledge individuals and organisational partners from eight countries who contributed to data collection for the childbirth and newborn care assessments and provided support during the development of this manuscript.

Collaborators The following are members of the Western Pacific Region Early Essential Newborn Care Working Group in alphabetical order: Annie Jatobatu (Ministry of Health of Solomon Islands, Honiara, Solomon Islands), Anthony Calibo (Department of Health of the Philippines, Manila, Philippines), Baldan Tsevelmaa (Ministry of Health of Mongolia, Ulaanbaatar, Mongolia), Bounnack Saysanasongkham (Ministry of Health of Lao People's Democratic Republic, Vientiane, Laos PDR), Divinal Ogaoga (Ministry of Health of Solomon Islands, Honiara, Solomon Islands), Edward Joseph Waramin (National Department of Health, Port Moresby, Papua New Guinea), Elizabeth Mary Mason (London School of Hygiene and Tropical Medicine, London, UK), Hiromi Obara (National Centre for Global Health and Medicine, Tokyo, Japan), Hoang Thi Tran (Da Nang Hospital for Women and Children, Da Nang, Viet Nam), Hoang Anh Tuan (Ministry of Health of Viet Nam, Hanoi, Viet Nam), Howard Sobel (World Health Organization Regional Office for the Western Pacific), Jacqueline Kitong (Office of the WHO Representative in the Philippines, Manila, Philippines), Jessica Mara Yaipupu (Office of the WHO Representative in Papua New Guinea, Port Moresby, Papua New Guinea), John Murray (World Health Organization Regional Office for the Western Pacific), Kannitha Cheang (Office of the WHO Representative in Cambodia, Phnom Penh Cambodia), Maria Asuncion Silvestre (Kalusugan ng Mag-Ina (KMl; translation Health of Mother and Child), Quezon City, Philippines), Outhevanh Kounnavongsa (Office of the WHO Representative in Laos PDR, Vientiane, Laos PDR), Pamela Putney (International Consultant, Martha's Vineyard, USA), Pham Thi Quynh Nga (Office of the WHO Representative in Viet Nam, Hanoi, Viet Nam), Priya Mannava (World Health Organization Regional Office for the Western Pacific), Rathavy Tung (Ministry of Health of Cambodia, Phnom Penh, Cambodia), Sano Phal (Office of the WHO Representative in Cambodia, Phnom Penh, Cambodia), Shogo Kubota (Office of the WHO Representative in Laos PDR, Vientiane, Laos PDR), Sidonn Krang (Ministry of Health of Cambodia, Phnom Penh, Cambodia), Simon Burggraaf (Office of the WHO Representative in Solomon Islands, Honiara, Solomon Islands), Sommana Rattana (Ministry of Health of Lao People's Democratic Republic, Vientiane, Laos PDR), Tao Xu (Chinese Center for Disease Control and Prevention, Beijing, China), Tuohong Zhang (Office of the WHO Representative in China, Beijing, 
China), Ulziihutag Enkhmaa (Ministry of Health of Mongolia, Ulaanbaatar, Mongolia), Vanya Delgermaa (Office of the WHO Representative in Mongolia, Ulaanbaatar, Mongolia), Y Meng Chhour (Ministry of Health of Cambodia, Phnom Penh, Cambodia) and Zhao Li (World Health Organization Regional Office for the Western Pacific).

Contributors ZL, PM, JCM and HLS conceptualised the study and developed the manuscript. ZL and PM carried out data cleaning and statistical analysis. HLS and JCM oversaw the quality and review process. All authors in the Western Pacific Region Early Essential Newborn Care Working Group supported the in-country data collection and validation, reviewed the manuscript and provided substantial inputs. All authors agreed on the submission of this manuscript.

Funding This study involved secondary analyses of data collected in eight countries. The original purpose of the data collection was to inform programme reviews and planning, which was supported and funded by Ministries of Health and the WHO Western Pacific Regional Office. No funds were used to conduct secondary data analyses or for manuscript development.

Disclaimer The authors alone are responsible for the views expressed in this article and they do not necessarily represent the views, decisions or policies of the institutions with which they are affiliated.

Competing interests None declared.

Patient consent for publication Not required.

Provenance and peer review Not commissioned; externally peer reviewed.

Data availability statement Data are available on request. Data sharing for pure research purposes is available on request.

Open access This is an open access article distributed in accordance with the Creative Commons Attribution Non Commercial (CC BY-NC 4.0) license, which permits others to distribute, remix, adapt, build upon this work non-commercially, and license their derivative works on different terms, provided the original work is properly cited, appropriate credit is given, any changes made indicated, and the use is non-commercial. See: http://creativecommons.org/licenses/by-nc/4.0/.

\section{REFERENCES}

1 Victora CG, Bahl R, Barros AJD, et al. Breastfeeding in the 21st century: epidemiology, mechanisms, and lifelong effect. Lancet 2016;387:475-90.

2 Kramer MS, Kakuma R. Optimal duration of exclusive breastfeeding. Cochrane Database Syst Rev 2012;32:62-3.

3 UNICEF. Capture the moment - early initiation of breastfeeding: the best start for every newborn, 2018. Available: https://data.unicef.org/ topic/nutrition/infant-and-young-child-feeding/ [Accessed 21 Jun 2019].

4 UNICEF. Infant and young child feeding - UNICEF DATA. Available: https://data.unicef.org/topic/nutrition/infant-and-young-childfeeding/ [Accessed 17 Dec 2018].

5 Sobel HL, Silvestre MAA, Mantaring JBV, et al. Immediate newborn care practices delay thermoregulation and breastfeeding initiation. Acta Paediatr 2011;100:1127-33.

6 Save the Children. A situational analysis of newborn health and interventions in Vietnam: towards the development of a newborn health action plan, 2006. Available: https://www.healthynewbornne twork.org/hnn-content/uploads/Vietnam_English.pdf [Accessed 21 Jun 2019].

7 World Health Organization. Action plan for healthy newborn infants in the Western Pacific region (2014-2020), 2014. Available: http:// www.wpro.who.int/publications/regional_action_plan_newborn_ infants.pdf?ua $=1$

8 Obara H, Sobel H. Quality maternal and newborn care to ensure a healthy start for every newborn in the world Health organization Western Pacific region. BJOG 2014;121 Suppl 4:154-9.

9 Moore ER, Bergman N, Anderson GC, et al. Early skin-to-skin contact for mothers and their healthy newborn infants. Cochrane Database Syst Rev 2016;11:CD003519.

10 Widström A-M, Lilja G, Aaltomaa-Michalias P, et al. Newborn behaviour to locate the breast when skin-to-skin: a possible method for enabling early self-regulation. Acta Paediatr 2011;100:79-85.

11 World Health Organization. Evidence for the ten steps to successful breastfeeding, 1998. Available: https://www.who.int/nutrition/ publications/evidence_ten_step_eng.pdf

12 Prior E, Santhakumaran S, Gale C, et al. Breastfeeding after cesarean delivery: a systematic review and meta-analysis of world literature. Am J Clin Nutr 2012;95:1113-35.
13 Sharma IK, Byrne A. Early initiation of breastfeeding: a systematic literature review of factors and barriers in South Asia. Int Breastfeed $J$ 2016;11:17.

14 Rowe-Murray HJ, Fisher JRW. Baby friendly Hospital practices: cesarean section is a persistent barrier to early initiation of breastfeeding. Birth 2002;29:124-31.

15 World Health Organization. Protecting, promoting and supporting breastfeeding: the special role of maternity services. A joint WHO/ UNICEF statement. Geneva, 1989.

16 Pérez-Escamilla R, Martinez JL, Segura-Pérez S. Impact of the Baby-friendly Hospital initiative on breastfeeding and child health outcomes: a systematic review. Matern Child Nutr 2016;12:402-17.

17 Clavano NR. Mode of feeding and its effect on infant mortality and morbidity. J Trop Pediatr 1982;28:287-93.

18 Silvestre MAA, Mannava P, Corsino MA, et al. Improving immediate newborn care practices in Philippine hospitals: impact of a national quality of care initiative 2008-2015. Int J Qual Health Care 2018;30:537-44.

19 World Health Organization Regional Office for the Western Pacific. Second biennial progress report: 2016-2017 (action plan for health newborn infants in the Western Pacific region: 2014-2020), 2017. Available: http://iris.wpro.who.int/bitstream/handle/10665.1/14094/ 9789290618492-eng.pdf

20 World Health Organization. Guideline: protecting, promoting and supporting breastfeeding in facilities providing maternity and newborn services, 2017.

21 World Health Organization. Who recommendations on newborn health: guidelines Approved by the who guidelines review Committee. Geneva, 2017.

22 Sobel HL, lellamo AD, Raya RR, et al. The economic burden of infant formula on families with young children in the Philippines. J Hum Lact 2012;28:174-80.

23 World Health Organization. International Code of marketing of breast-milk substitutes. Geneva, 1981.

24 World Health Organization Regional Office for the Western Pacific. Annual implementation review and planning guide (early essential newborn care, module 1), 2016. Available: http://iris.wpro.who.int/ bitstream/handle/10665.1/13978/9789290618362-eng.pdf

25 World Health Organization. Who recommendations: intrapartum care for a positive childbirth experience, 2018. Available: https:// apps.who.int/iris/bitstream/handle/10665/260178/9789241550215eng.pdf;jsessionid=7E800B590A164DC7FC879E73B480D6FC? sequence=1 [Accessed 29 Jan 2020]

26 Murray EK, Ricketts S, Dellaport J. Hospital practices that increase breastfeeding duration: results from a population-based study. Birth 2007;34:202-11.

27 Hobbs AJ, Mannion CA, McDonald SW, et al. The impact of caesarean section on breastfeeding initiation, duration and difficulties in the first four months postpartum. BMC Pregnancy Childbirth 2016;16:90.

28 Bramson L, Lee JW, Moore E, et al. Effect of early skin-to-skin mother--infant contact during the first 3 hours following birth on exclusive breastfeeding during the maternity hospital stay. J Hum Lact 2010;26:130-7.

29 Mikiel-Kostyra K, Mazur J, Bołtruszko I. Effect of early skin-to-skin contact after delivery on duration of breastfeeding: a prospective cohort study. Acta Paediatr 2002;91:1301-6.

30 Maeda Y, Takahashi K, Yamamoto K, et al. Factors affecting the provision of analgesia during childbirth, Japan. Bull World Health Organ 2019;97:631-6.

31 Righard L, Alade MO. Effect of delivery room routines on success of first breast-feed. Lancet 1990;336:1105-7.

32 Widström A-M, Brimdyr K, Svensson K, et al. Skin-to-skin contact the first hour after birth, underlying implications and clinical practice. Acta Paediatr 2019;108:1192-204.

33 World Health Organization. World Health organization recommendations for augmentation of labour, 2014. Available: http:// apps.who.int/iris/bitstream/10665/112825/1/9789241507363_eng. pdf?ua=1 [Accessed 29 Jan 2020].

34 Howard C, Howard F, Lawrence R, et al. Office prenatal formula advertising and its effect on breast-feeding patterns. Obstet Gynecol 2000;95:296-303.

35 Dulon M, Kersting M, Bender R. Breastfeeding promotion in nonUNICEF-certified hospitals and long-term breastfeeding success in Germany. Acta Paediatr 2007;92:653-8.

36 Stremler J, Lovera D. Insight from a breastfeeding peer support pilot program for husbands and fathers of Texas WIC participants. J Hum Lact 2004;20:417-22.

37 Kistin N, Abramson R, Dublin P. Effect of peer counselors on breastfeeding initiation, exclusivity, and duration among low-income urban women. J Hum Lact 1994;10:11-15. 
38 Renfrew MJ, McCormick FM, Wade A, et al. Support for healthy breastfeeding mothers with healthy term babies. Cochrane Database Syst Rev 2012:CD001141.

39 World Health Organization. Contemporary patterns of breast-feeding: report on the who Collaborative study on breast-feeding. Geneva, 1981.

40 Sobel HL, lellamo A, Raya RR, et al. Is unimpeded marketing for breast milk substitutes responsible for the decline in breastfeeding in the Philippines? an exploratory survey and focus group analysis. Soc Sci Med 2011;73:1445-8.

41 Putthakeo P, Ali M, Ito C, et al. Factors influencing breastfeeding in children less than 2 years of age in Lao PDR. J Paediatr Child Health 2009;45:487-92

42 Raya RR. The Philippine breastfeeding struggle continues. Lancet 2008;371:794-5.

43 World Health Organization Regional Office for the Western Pacific. Coaching for the First Embrace: Facilitator's Guide, 2016. Available: http://www.wpro.who.int/publications/regional_action_plan_ newborn_infants.pdf?ua=1

44 World Health Organization Regional Office for the Western Pacific. Introducing and sustaining EENC in hospitals: routine childbirth and newborn care (module 3), 2016. Available: https://iris.wpro. who.int/bitstream/handle/10665.1/13409/9789290617808-eng.pdf [Accessed 27 Jun 2019].

45 Tran HT, Mannava P, Murray JCS, et al. Early essential newborn care is associated with reduced adverse neonatal outcomes in a tertiary hospital in dA Nang, Viet Nam: a pre- post- intervention study. EClinicalMedicine 2018;6:51-8.

46 World Health Organization Regional Office for the Western Pacific. Progress reports on technical programmes, regional Committee, 2019. Available: https://www.who.int/docs/default-source/wprodocuments/regional-committee/session-69/working-documents/ wpr-rc69-10-progress-reports-on-tech-programmes.pdf?sfvrsn= 97e8bacf_4

47 Grummer-Strawn LM, Scanlon KS, Fein SB. Infant feeding and feeding transitions during the first year of life. Pediatrics 2008;122 Suppl 2:S36-42.

48 Patterson JA, Keuler NS, Olson BH. The effect of maternity practices on exclusive breastfeeding rates in U.S. hospitals. Matern Child Nutr 2019;15:e12670. 